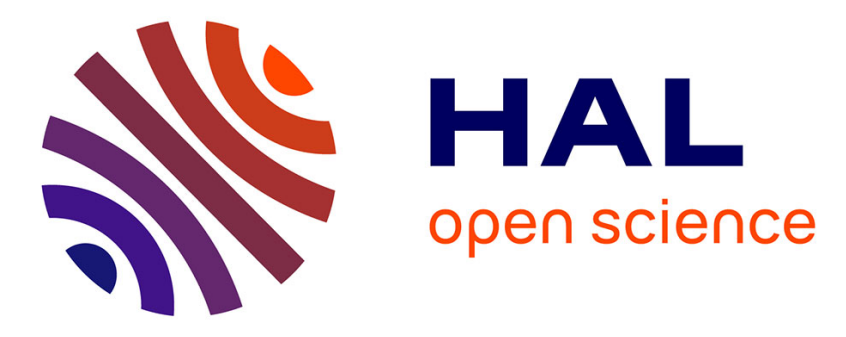

\title{
Optimal Sizing Of Battery Energy Storage System For An Islaned Microgrid
}

Pham Minh Cong, Tran Quoc Tuan, Ahmad Hably, Seddik Bacha, Luu Ngoc An

\section{- To cite this version:}

Pham Minh Cong, Tran Quoc Tuan, Ahmad Hably, Seddik Bacha, Luu Ngoc An. Optimal Sizing Of Battery Energy Storage System For An Islaned Microgrid. IECON 2018 - 44th Annual Conference of the IEEE Industrial Electronics Society, Oct 2018, Washington, DC, United States. hal-01895350

\section{HAL Id: hal-01895350 \\ https://hal.science/hal-01895350}

Submitted on 15 Oct 2018

HAL is a multi-disciplinary open access archive for the deposit and dissemination of scientific research documents, whether they are published or not. The documents may come from teaching and research institutions in France or abroad, or from public or private research centers.
L'archive ouverte pluridisciplinaire HAL, est destinée au dépôt et à la diffusion de documents scientifiques de niveau recherche, publiés ou non, émanant des établissements d'enseignement et de recherche français ou étrangers, des laboratoires publics ou privés. 


\title{
OPTIMAL SIZING OF BATTERY ENERGY STORAGE SYSTEM FOR AN ISLANED MICROGRID
}

\author{
M.C. Pham ${ }^{\diamond, *}$, T. Q. Tran ${ }^{*}$, A. Hably $~ '$, S. Bacha ${ }^{\diamond}$, Luu Ngoc An $\bullet$
}

\begin{abstract}
This paper demonstrates a double layer optimization strategy to determine the optimum size of battery energy storage system (BESS) considering the EMS of a microgrid (MG). In the developed model, the BESS sizing problem is viewed as the outer optimal loop and the economic dispatch of MG based on BESS data from the outer loop is considered as inner loop. An iterative method and a dynamic programming (DP) method are utilized to solve the optimal problems for outer and inner models respectively. A simulator is built in MATLAB environment for an island microgrid is used to evaluate the efficiency of the proposed method.
\end{abstract}

\section{INTRODUCTION}

In order to minimize the use of fossil fuel production and to limit their impact on the global warming, grid operators tires to maximize of the integration of renewable energy sources (RESs). A microgrid (MG) is a small-scale power supply network with loads, renewable energy sources (RES), distributed generation (DG), and energy storage systems (ESS). Two different modes of operation: the isolated mode and the grid-connected mode [1]. In this present paper, we will focus on a isolated mode MG power system integrating RESs also know as islanded microgrid. One of the most significant challenges in islanded MG is balancing the energy between customers demand and the intermittent suppliers. A Battery ESS (BESS) with the abilities of mitigating load mismatch and easing the integration of renewable energy (RE) can be considered from the best choices for maintaining stability and enhancing power quality in islanded system [2]. However, the main drawback of BESS is the high investment cost and short life cycle. Thus, sizing the BESS respecting both technical and economic constrains is very crucial in a real implementation.

There are three popular approaches to deal with sizing BESS [3]: energy balance approach, fluctuations stabilize approach, and the economic optimization approach. In [4], the authors follow the first approach by using the Loss of Power Supply Probability (LPSP), which ensures the power reliability of the system. In addition, in [3], a Discrete Fourier Transform is used for sizing BESS in order to compensate the imbalance power in the microgrid. To reduce the mismatch between load and wind generation in an islanded system, a Probabilistic approach is used in [5]. On the other side, in [6], the optimal size of BESS is determined by Frequency Containment Reserve (FCR). The

\footnotetext{
Univ. Grenoble Alpes, CNRS, Grenoble INP, G2elab, GIPSA-lab, 38000 Grenoble, France ahmad. hablydgrenoble-inp. fr

* Alternative Energies and Atomic Energy Commission (CEA), Grenoble, France

- Danang University of Science and Technology, Da Nang, Viet Nam
}

BESS provides the service for reducing frequency deviation. Moreover, in order to maintain the specific tolerance $( \pm 0.05$ pu of error for $90 \%$ of the time) in the system with high wind energy penetration, the authors [7] have used a method called Predictive Controller for optimizing the size of BESS. An economic approach is also recommended in the before-mentioned paper. In [8], and by using Improved Harmony Search Algorithm (IHSA), the size of BESS is designed to optimize the total annual operating cost of the MG, with the moderating of state of charge (SOC) limitation. [3] presented a twostage strategy for sizing the BESS with respecting to optimal MG operation by applying Mesh Adaptive Direct Search (MADS) and an improved particle swarm optimization (IPSO) algorithm.

Following the economic optimization approach, the main purpose is to evaluate the optimum BESS size, considering the energy management system of the islanded microgrid.

This present paper is organized as follows. First, the researched microgrid is defined and modeled in Section II. Next, in Section III, the optimization problems are formulated. Subsequently, suitable methodologies are proposed in Section IV. Section V indicates the results for the simulation and concluding remarks are presented in Section VI.

\section{CONFIGURATION OF THE SYSTEM}

The microgrid model studied in this paper represents a hybrid system with different elements (see Figure 1). The microgrid system comprises distibuted DERs as a Photovoltaic (PV) system and a Wind farm (Wind). Furthermore, the system will have a backup diesel generator for covering surplus power.

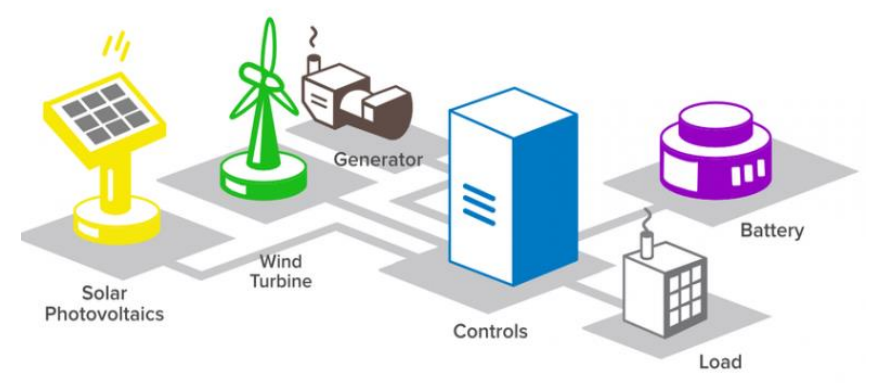

Fig. 1. The illustrated isolated MG system. 


\section{A. Photovoltaic system}

The hourly data of the photovoltaic system is forecasted is shown on Figure 2. As it is shown, the peak of PV production reaches around $6 \mathrm{MW}$ in the middle of the day. It is also clear that there is no production at night.

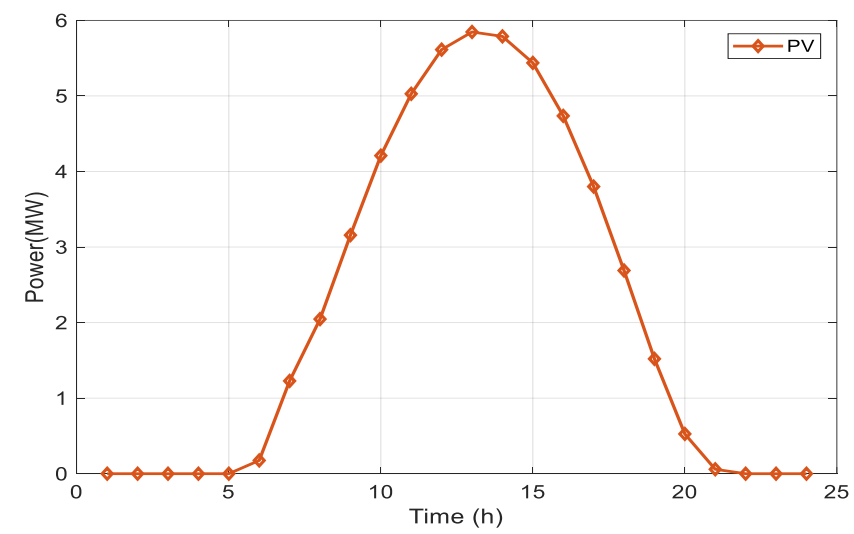

Fig. 2. The daily PV production curve.

\section{B. Wind system}

The predicted of Wind production is indicated Figure 3. The maximum power point of Wind farm production is 2.5 MW. The variability of the production is also taken into account.

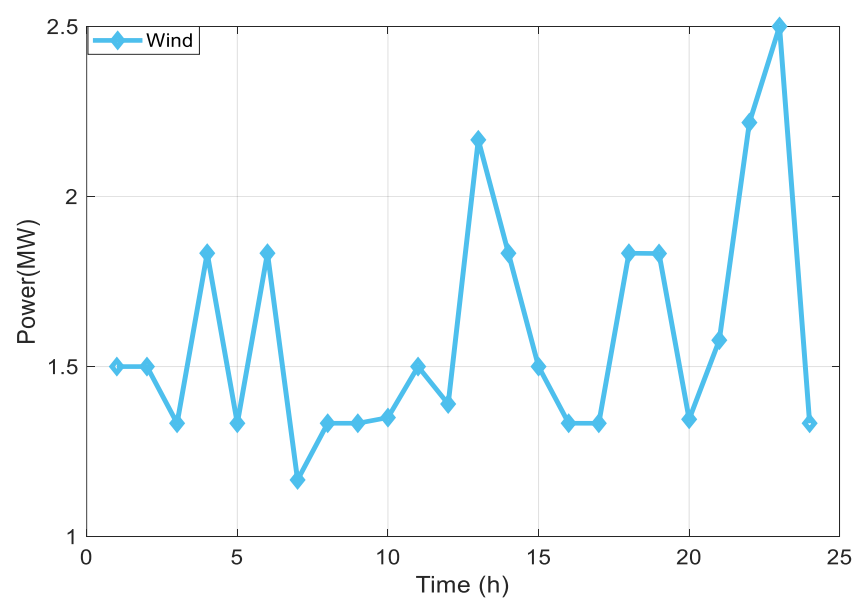

Fig. 3. The daily Wind farm production curve.

\section{The battery energy storage systes}

The battery energy storage system (BESS) size will be evaluated in the outer optimization level as it will be shown later in the iterative method. The capacity for BESS capacity is simulated from the minimum to the maximum value. In order to satisfy the energy balance in the microgrid, BESS not only has to be able to provide deficient of the demand energy from the load when the power from DERs is not enough but also it has to be able absorb the surplus energy. In this present paper, LeadAcid battery is used as BESS.
From [3], the minimum capacity for BESS $\left(E_{B E S S}^{M i n}\right)$ can be determined as:

$$
E_{B E S S}^{M i n}=\max \left\{E_{\text {dis }}^{M i n}, E_{c h}^{M i n}\right\}
$$

where

$$
E_{d i s}^{M i n}=\int_{0}^{T}\left(P_{L}-P_{M G}^{M a x}\right) \quad \text { if } \quad P_{M G}^{M a x}<P_{L}
$$

and

$$
E_{d i s}^{M i n}=\int_{0}^{T}\left(P_{M G}^{M a x}-P_{L}\right) \quad \text { if } \quad P_{M G}^{M a x} \geq P_{L}
$$

with $E_{d} i s^{M} i n$ and $E_{c} h^{M} i n$ are respectively the minimum energy providing provided by the BESS and the minimum energy absorbed by BESS. $P_{M G}^{M a x}$ is the maximum production in the MG. Therefore, following equation 1, the minimum capacity of BESS in the MG system is estimated to $7.8 \mathrm{MWh}$ and the maximum capacity for BESS is $117 \mathrm{MWh}$ which is enough to cover the load for one day without any RES. Thus, the optimum value of capacity of BESS will be taken between 7.8 MWh and $117 \mathrm{MWh}$.

The state of charge $(S O C)$ of BESS can be calculated as follows:

$$
S O C=\frac{C(t)}{C_{R e f}(t)}
$$

where $C(t)$ is the capacity at each instant and $C_{R e f}(t)$ is the reference capacity of BESS. Furthermore, the $S O C$ at time $t$ can be formulated by the discrete equation:

$$
S O C(t)=S O C(t-1)+\frac{P_{M G}(t)-P_{L}(t)}{C_{R e f}(t)} \cdot \Delta t
$$

\section{Loads profile}

The load profile utilized in this present paper is based on a daily load curve as shown in Figure 4. As it is shown, there is a consumption peak around noon.

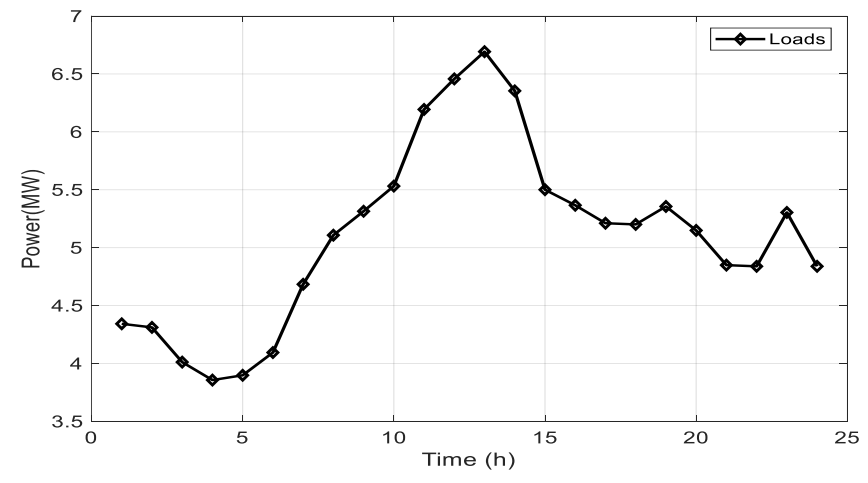

Fig. 4. The daily load curve.

\section{E. Diesel generator}

The diesel generator to be used has to cover the entire load demand in the case of unavailability of RESs and BESS. 


\section{PROBLEM FORMULATION}

The relationship between the optimal capacity of BESS and the optimal energy management in MG is tricky mission. Thus, in this section, the problems will be separated into two parts represented in two loops in Figure 5. In the inner loop, the energy management system using the dynamic programming (DP). The operation cost is minimized in the outer loop. As mentioned above, the objective is to minimize

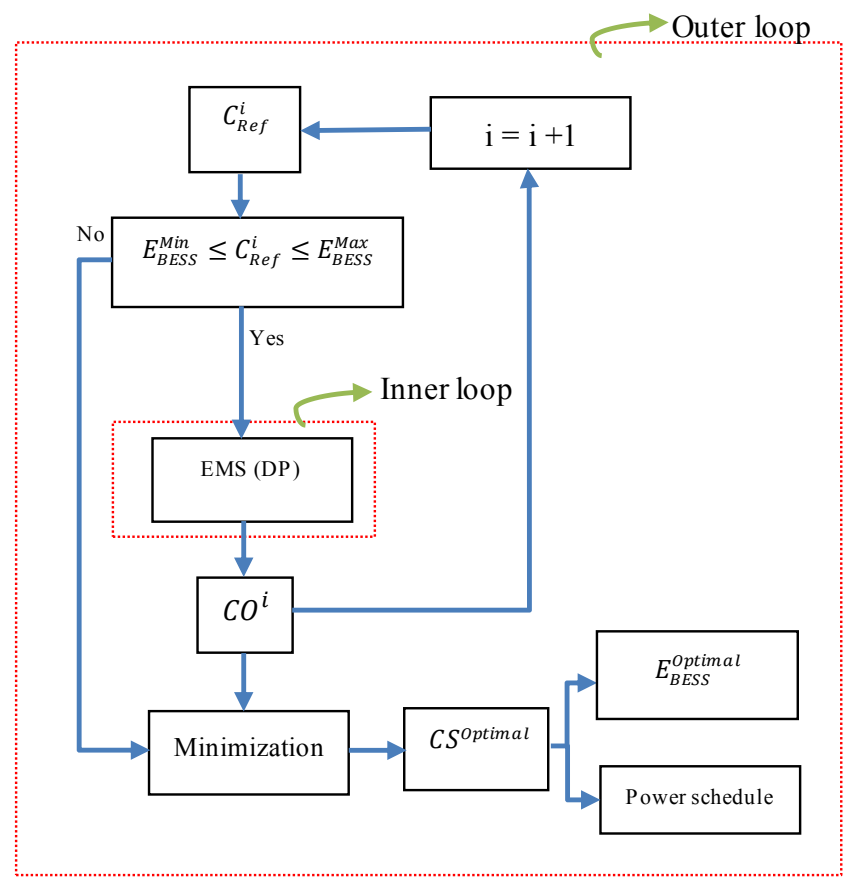

Fig. 5. The flowchart of the proposed method.

the cost of MG operation (CO) as the one used in [9]:

$$
\min (C O)=\min \left(\sum_{1}^{T} F C(t)+E C(t)+B_{r} C(t)\right)
$$

As shown in Equation 6, the cost of MG operation $(C O)$ does comprise not only the cost of fuel $(F C)$ and emission cost $(E C)$ but also does include the battery replacement cost $\left(B_{r} C\right)$. Here, we will list the details of elements of the objective function. First, we have

$$
F C=\sum_{t=1}^{T} C_{f} \cdot F(t)
$$

where $C_{f}$ is the fuel cost per liter and $F(t)$ is the hourly consumption of diesel generator. Second, $F(t)$ can be calculated as following:

$$
F(t)=\left(0.246 P_{D G}(t)+0.08415 P_{R}\right)
$$

with $P_{R}$ is the rated power of diesel generators and $P_{D G}(t)$ the diesel power at time instant $t$. The second element of objective function, emission cost, $E C(t)$ can be expressed by the following equation:

$$
E C=\sum_{t=1}^{T} \frac{E_{f} E_{c f} P_{D G}(t)}{1000}
$$

where $E_{f}$ is the emission function $(\mathrm{kg} / \mathrm{kWh})$ and $E_{c f}$ represents the emission cost factor. Finally, the last element of the objective function $B_{r} C(t)$ is expressed by:

$$
B_{r} C(t)=B_{i} C \frac{\Delta S O H(t)}{1-S O H_{\text {min }}}
$$

with $S O H$ is the State Of Health of the BESS and $B_{i} C$ is the batteries investment cost.

Subsequently, the constraints in the system are presented by the following :

- Power balance constraints:

$$
P_{L}(t)=P_{P V}(t)+P_{B}(t)+P_{D G}(t)+P_{W i n d}(t)
$$

- BESS constraints:

$$
\begin{aligned}
\Delta S O C_{\min } & \leq \Delta S O C(t) \leq \Delta S O C_{\max } \\
S O C_{\min } & \leq S O C(t) \leq S O C_{\max } \\
S O H(t) & \geq S O H_{\min }
\end{aligned}
$$

- Diesel generator constraint:

$$
P_{D G_{\min }} \leq P_{D}(t)(t) \leq P_{D G_{\max }}
$$

On the other hand, the outer loop uses an iterative method. The values of BESS capacity are varied in a predefined range and will be used as the input for the first node in the inner optimization loop as shown in Figure 5. After that, the optimal of capacity of BESS, following with the operation cost of MG and the energy schedule can be figured out.

\section{Methodologies}

Within the outer loop, the capacity of BESS is provided. In this layer, the iterative method is used to modify the value of capacity which is limited in Section II. With each value of capacity of BESS, we will have a different input for the inner loop, that will lead to different scenarios for energy schedule and the cost of operation. The most appropriate capacity will be the one that establish the minimum cost of operation.

With the inner loop, the idea is to describe the optimization problem of EMS through SOC of BESS, with the use of Dynamic Programming with Bellman algorithm. Thanks to power balance constraint, one has:

$$
P_{B}(t)=P_{L}(t)-P_{P V}(t)-P_{W i n d}(t)-P_{D G}(t)
$$

From the above equation, we transform it into the energy balance formula:

$$
\begin{aligned}
S O C(t)= & S O C(t-1)+ \\
& \frac{-P_{L}(t)+P_{P V}(t)+P_{W i n d}(t)+P_{D G}(t)}{C_{\text {ref }}} \Delta t
\end{aligned}
$$

Where the state of charge is defined as in Equation 4 with $C(t)$ and $C_{r e f}$ are respectively the BESS capacity at time $t$ and the reference capacity. $\Delta t$ is is a unit time period which is chosen here to be equal to 1 hour. From Equation 18 , we can see that, by controlling the SOC of BESS, we can control the $P_{D G}$ with the forecasted energy profiles of 
RES and loads. Thus, we can find the best SOC profile in order to minimize the operation cost of the system. Now, the SOC is illustrate as Figure 6. The purpose of the inner optimization loop is to find the flow from the initial node to the end node. As we can see that the structure of the system can be modeled by a graph. Now, we calculate the weight of each node in the first layer, which receives the information from the beginning node. On the other hand, in order to calculate the weight of each node in the second layer, which receives the information from all nodes in the first layer by determining the minimization of the $C O$ from the beginning node. Repeat this concept until the weights of nodes in the last layer are obtained. Then, we aim to calculate the weight of the end node that receives the information from all nodes at the last layer by defining the the minimization of the cash flow from the beginning node. And finally, we can determine the minimization of the flow from the beginning node to final node. Therefore, this method can be applied to determine the optimal the cost of MG operation.

0

Time (h)

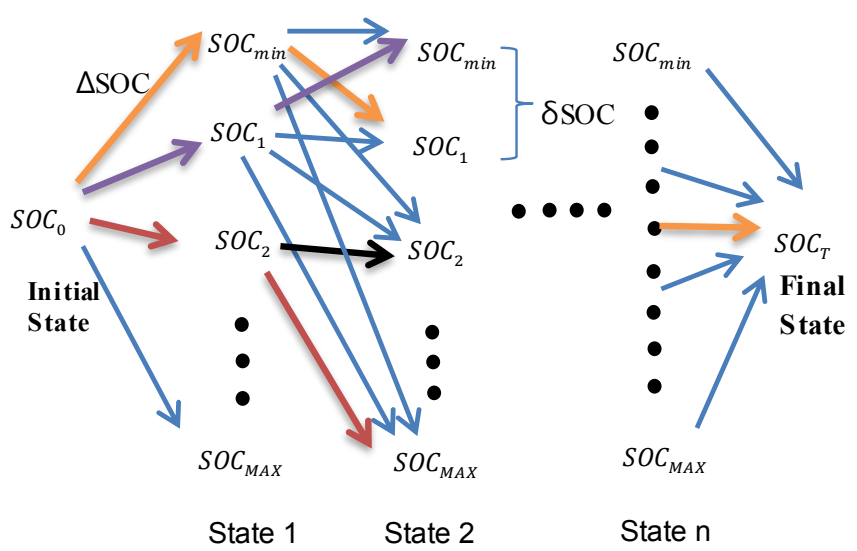

Fig. 6. Dynamic Programming for energy management based on SOC of BESS.

\section{Simulation RESUlts}

Firstly, the input parameters for the microgrid system is set up in Table I. The maximum and minimum capacity for the BESS are predefined in Section II. In addition, in order to preserve the battery, the maximum values of state of charge and discharge for BESS are respectively 0.9 and $0.2 \mathrm{pu}$. The initial and the final values of SOC of BESS are set at 0.5, which is the most sufficient rate for absorbing or providing energy for the system in term of next day preparation. The number of state $(N)$ at each period can be calculated:

$$
N=\frac{S 0 C_{\max }-S 0 C_{\min }}{\delta S 0 C}
$$

Following the above equation we get that $N$ is equal to 700 states. Running the proposed algorithm with the input values in Table I, we get the optimal power schedule shown in Figure 7. Also we get the optimal capacity for BESS which
TABLE I

THE INPUT VALUES FOR THE SIMULATION STUDY

\begin{tabular}{lll}
\hline Name & Value & Unit \\
\hline$E_{B E S S}^{M i n}$ & 7.8 & $\mathrm{MWh}$ \\
$E_{B \text { Max }}^{M E}$ & 117 & $\mathrm{MWh}$ \\
$S 0 C_{0}$ & 0.5 & $\mathrm{pu}$ \\
$S 0 C_{T}$ & 0.5 & $\mathrm{pu}$ \\
$S 0 C_{\min }$ & 0.2 & $\mathrm{pu}$ \\
$S 0 C_{\max }$ & 0.9 & $\mathrm{pu}$ \\
$S O H_{\min }$ & 0.7 & $\mathrm{pu}$ \\
$\delta S 0 C$ & 0.001 & $\mathrm{pu}$ \\
$\triangle S O C$ & & $\mathrm{pu}$ \\
Cost of battery bank & 200 & $\$$ per kWh \\
Minimum power of diesel & 1.55 & $\mathrm{MWh}$ \\
generator & & \\
Maximum power of diesel & 5.15 & $\mathrm{MWh}$ \\
generator & & \\
Fuel cost & 0.7 & $\$$ per 1 \\
\hline
\end{tabular}

is equal to $8 \mathrm{MWh}$ and the optimal cost of the operation which is evaluated to $\$ 11115$.

It can be seen that the load demand is satisfied by the DERs. As illustrated in Figure 7, at the beginning of the day, the load is not fully covered by the wind farm so the diesel generator is activated to compensate the deficit energy. In contrast, from 6 a.m to 8 a.m, under the proposed methodology, in order to achieve the optimum cost of operation, the diesel generator is turn off to make a way for BESS system. Moreover, from 10 a.m to 5 p.m, when the production from Photovoltaic and Wind reaches the highest values, the BESS ingests the surplus energy. Therefore, the BESS is not only providing charge and discharge to keep the power balance in the system but also the operation cost of the MG is minimized. The diesel generator rests for 11 hours/day, which is a very good operating condition and reduces a lot of $\mathrm{CO}_{2}$ emissions. Figure 8 suggests the state

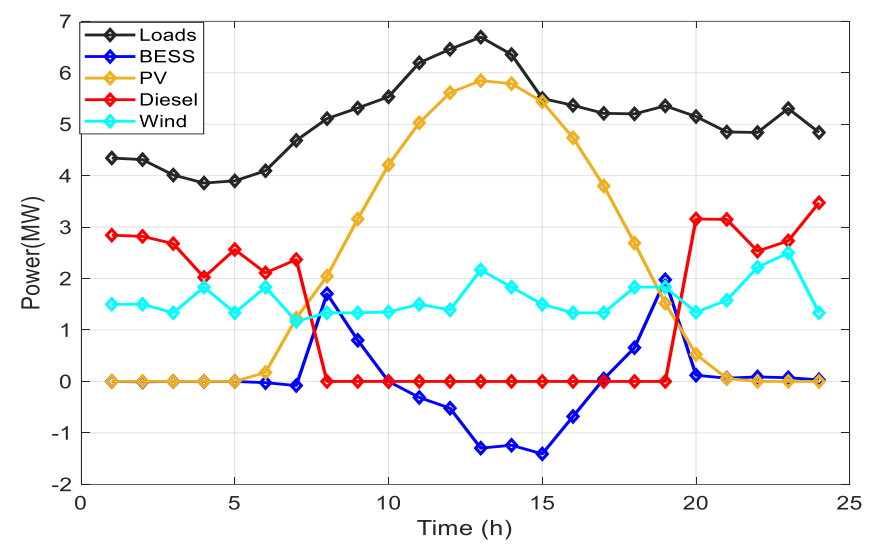

Fig. 7. The optimal power schedule of the islanded microgrid.

of charge curve for the BESS in a day ahead schedule. The SOC of BESS at the beginning and at the end of the day is successfully fixed at 0.5 , which is accomplished by Dynamic Programming algorithm. 


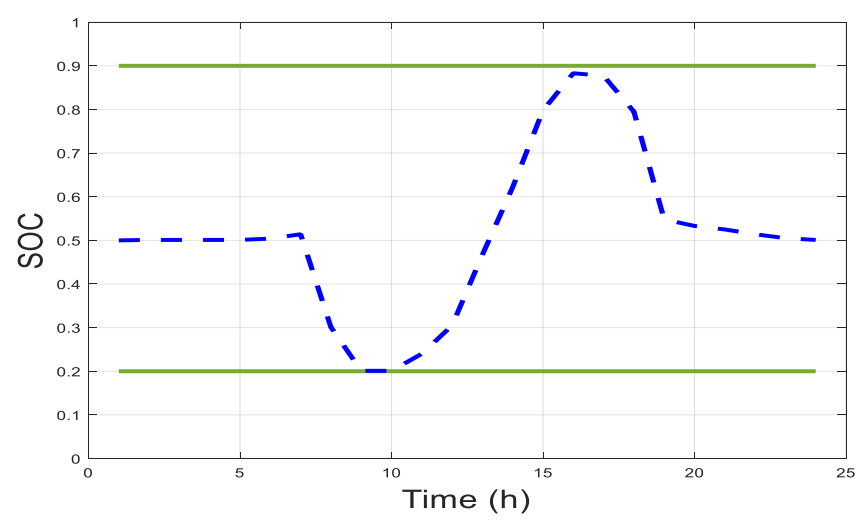

Fig. 8. The optimal SOC curve of BESS.

\section{CONCLUSIONS}

In this paper, the BESS sizing problem and the optimal energy management for islanded MG have been taken into account. The model for optimization problem is developed and the Dynamic Programming with the iterative outer loop is utilized to find the optimal values. The proposed method gives the best value for BESS capacity for the system and introduces the power schedule achieves global energy optimization.

\section{REFERENCES}

[1] H. Al-Nasseri, M. Redfern, and R. O'Gorman, "Protecting micro-grid systems containing solid-state converter generation," in Future Power Systems, 2005 International Conference on. IEEE, 2005, pp. 5-pp.

[2] R. L. Vasquez-Arnez, D. S. Ramos, and T. E. Del Carpio-Huayllas, "Microgrid dynamic response during the pre-planned and forced islanding processes involving dfig and synchronous generators," International Journal of Electrical Power \& Energy Systems, vol. 62, pp. 175-182, 2014.

[3] H. Xiao, W. Pei, Y. Yang, and L. Kong, "Sizing of battery energy storage for micro-grid considering optimal operation management," in Power System Technology (POWERCON), 2014 International Conference on. IEEE, 2014, pp. 3162-3169.

[4] I. Sansa, R. Villafafila, and N. M. Bellaaj, "Optimal sizing design of an isolated microgrid using loss of power supply probability," in Renewable Energy Congress (IREC), 2015 6th International. IEEE, 2015, pp. 1-7.

[5] T. M. Masaud, O. Oyebanjo, and P. Sen, "Sizing of large-scale battery storage for off-grid wind power plant considering a flexible wind supply-demand balance," IET Renewable Power Generation, vol. 11, no. 13 , pp. 1625-1632, 2017.

[6] L. Cupelli, N. Barve, and A. Monti, "Optimal sizing of data center battery energy storage system for provision of frequency containment reserve," in Industrial Electronics Society, IECON 2017-43rd Annual Conference of the IEEE. IEEE, 2017, pp. 7185-7190.

[7] I. N. Moghaddam, B. H. Chowdhury, and S. Mohajeryami, "Predictive operation and optimal sizing of battery energy storage with high wind energy penetration," IEEE Transactions on Industrial Electronics, vol. 65, no. 8, pp. 6686-6695, 2018.

[8] C. K. Nayak and M. R. Nayak, "Optimal design of battery energy storage system for peak load shaving and time of use pricing," in Electrical, Computer and Communication Technologies (ICECCT), 2017 Second International Conference on. IEEE, 2017, pp. 1-7.

[9] N. A. Luu, "Control and management strategies for a microgrid," Ph.D. dissertation, Université Grenoble Alpes, 2014 